\title{
МЕЖГОДОВАЯ ИЗМЕНЧИВОСТЬ СОЛЕНОСТИ И ВЕРТИКАЛЬНОЙ ТЕРМОХАЛИННОЙ УСТОЙЧИВОСТИ В РАЗЛИЧНЫХ РАЙОНАХ АЗОВСКОГО МОРЯ В ЛЕТНИЙ ПЕРИОД 1992-2016 ГГ.
}

\author{
А.Т. Кочергин ${ }^{1}$, С.В. Жукова ${ }^{2}$, Е.Ю. Малыгин ${ }^{3}$ \\ ${ }^{1}$ Керченский филиал («ЮгНИРО») Азовского научно-исследовательского института \\ рыбного хозяйства, РФ, г. Керчь, ул. Свердлова, 2 \\ E-mail: kochkerch@mail.ru \\ ${ }^{2}$ Азовский научно-исследовательский институт рыбного хозяйства, \\ РФ, г. Ростов-на-Дону, ул. Береговая, 21 В \\ E-mail: svezho51@gmail.com \\ ${ }^{3}$ Российский государственный гидрометеорологический университет, \\ РФ, г. Санкт-Петербург, Малоохтинский пр., 98 \\ E-mail: malygin-egor@mail.ru
}

По многолетним данным солености и вертикальной термохалинной устойчивости вод в летний период 1992-2016 гг. проанализирована межгодовая изменчивость этих параметров в различных районах Азовского моря. Выявлены тренды, циклы, амплитуды, проведено районирование моря по характеру временной изменчивости солености и вертикальной термохалинной устойчивости. Отмечены переломные годы в направленности межгодового хода анализируемых параметров, районы их относительно высокой и низкой динамики временной изменчивости.

Ключевые слова: Азовское море, соленость, устойчивость, межгодовая изменчивость, тренд, цикличность.

Введение. Соленость вод моря как важнейший абиотический фактор среды в значительной мере прямо и косвенно определяет состояние экосистемы моря. Азовское море относится к солоновато водным водоемам и по существу представляет собой большую зону смешения речных и черноморских вод $[1,2]$. Размеры Азовского моря и его мелководность являются причиной высокой изменчивости солености.

Ранее, на основе материалов за период 1960-2014 гг., были выявлены некоторые закономерности пространственновременной изменчивости солености Азовского моря [3]. В частности показаны периоды стабилизации, опреснения и осолонения, диапазон изменчивости солености и ее средние значения по различным районам моря и сезонам, межгодовой ход средней для моря солености за исследуемый период и годы экстремальных значений.

В 1976 г. средняя соленость всего моря достигала своего максимума $13,76 \%$, в 2006 г. минимума - 9,29\%о, без Таганрогского залива соответственно 14,04 и $9,64 \%$ в те же годы $[3,4]$. В современном периоде - 2006-2016 гг.
Азовское море характеризуется осолонением.

В пространстве, естественно, максимальные значения солености характерны для района у Керченского пролива, минимальные - для Таганрогского залива.

Вертикальная термохалинная устойчивость вод Азовского моря имеет отчетливо выраженный годовой ход, определяемый в основном годовым ходом температуры воды.

Пространственное распределение устойчивости находится в прямой зависимости от интенсивности адвекции речных вод в устьевых районах Дона и Кубани и черноморских вод в районе Керченского пролива, а также от гидрометеорологических условий над акваторией Азовского моря.

Наибольшие значения устойчивости наблюдаются в наиболее активных районах - Таганрогском заливе, устьевом взморье Кубани и районе, прилегающем к Керченскому проливу.

Состояние устойчивости вод Азовского моря определяется изменениями вертикального распределения температуры и солености, а также ветровой активности, способствующей выравниванию характеристик практически всей 
толщи вод Азовского моря. В многолетних колебаниях общей среднегодовой устойчивости собственно Азовского моря до 1990 г. отчетливо прослеживаются два периода повышенных значений (1963-1966 гг. и 1974-1981 гг.) и один семилетний период пониженных значений (1967-1973 гг.).

Стратификация водной толщи в теплый период года препятствует водообмену поверхностных и придонных слоев, насыщению последних кислородом вплоть до анаэробных ситуаций, что негативно влияет на условия существования гидробионтов [5].

Целью данной работы было проведение анализа межгодовой изменчивости солености и вертикальной термохалинной устойчивости вод (ВТХУВ) в различных районах Азовского моря, за исключением Таганрогского залива, за летние периоды (июль-август) 19922016 гг.

Материалы и методика. Принято районирование акватории Азовского моря на основе анализа интенсивности водообмена согласно [6, 7]. Совместный массив экспедиционных данных по солености АзНИИРХ и ЮгНИРО, ВТХУВ - АзНИИРХ за летние периоды (июльавгуст) 1992-2016 гг. в каждом из районов собственно Азовского моря, т.е. за исключением Таганрогского залива, позволил построить и проанализировать графики их межгодового хода и тренда.

ВТХУВ - рассчитывалась как вертикальный градиент плотности воды (с учетом температуры, солености и адиабатической поправки).

Результаты и обсуждения. Соленость. С 1960 по 2014 гг. наиболее высокое значение солености в море отмечалось в 1976 г. в 1-м районе - 14,66\%о, наиболее низкое $-8,63 \%$ в 2006 г. в 10-м районе [5]. В конце наблюдений (2016 г.) соленость, возраставшая с 2006 г. в большинстве районов, за исключением 3 -го, превысила значение $13 \%$, а в 1 -м предпроливном районе составила около 14\%o (рис. 2).

По диапазону межгодовой изменчивости районы собственно Азовского моря можно подразделить на 3 группы (рис.1 А):

- первая группа районов с амплитудой изменчивости $<4,0 \%$ - крайние западный (№ 3) и восточный (№ 10) райо- ны с минимальным смешением относительно соленых вод Керченского пролива и относительно пресных вод Таганрогского залива;

- вторая группа северных районов (№ 5,6$)$ имела амплитуду $4,0-4,5 \%$ и характеризовалась превалирующим воздействием относительно пресных вод Таганрогского залива при преобладающих северо-восточных и восточных ветpax;

- третья группа, в основном южные и центральные районы $(1,2,4,9,11,12)$, отличалась повышенной амплитудой межгодовой изменчивости - более 4,5\%.

Цикличность изменчивости по районам, за исключением 11-го предпроливного района, имеет два различных периода: короткоцикличный до 2001-2004 гг. и длинноцикличный после (рис. 2). Первый период характеризовался циклами изменчивости в основном 2-5 лет, в 12-м центральном районе - 2-7 лет; второй - в основном 515 лет. В первый период, в 3-м северозападном районе в конце срока проявился короткий двухгодичный цикл.

В 11-м предпроливном районе цикличность весь период - 2-6 лет.

Межгодовой ход солености по тренду подразделяется на 2 периода:

- до 2006 г., когда наблюдался отрицательный тренд при относительно низкой амплитуде колебаний - 1,78-3,58\% (рис. 2);

- после 2006 г. с резко положительным трендом и относительно высокой амплитудой изменчивости - 3,175,57 \%, превышающей в 1,45-2,56 раза амплитуду предшествующего периода.

В период 1992-2006 гг. изменчивость солености имела разнонаправленный характер, а в период 2006-2016 гг. относительно однонаправленный, характеризовавшийся стабильным осолонением.

ВТХУВ. По амплитуде межгодовой изменчивости ВТХУВ районы Азовского моря в летние периоды 1992-2016 гг. можно подразделить на 3 группы: с большой амплитудой - $16,8-47,4$, средней $-7,3-16,7$ и малой $-3,7-6,0$ тыс. усл. ед. и соответственно со значениями в диапазоне $-3,5 \div 44,7,-1,6 \div 15,9$ и $0,3 \div 6,0$ тыс. усл. ед. (табл. 1, 2; рис. 1 В, $3)$; т.е. с высокой, средней и низкой степенью изменчивости стратификации вод. 

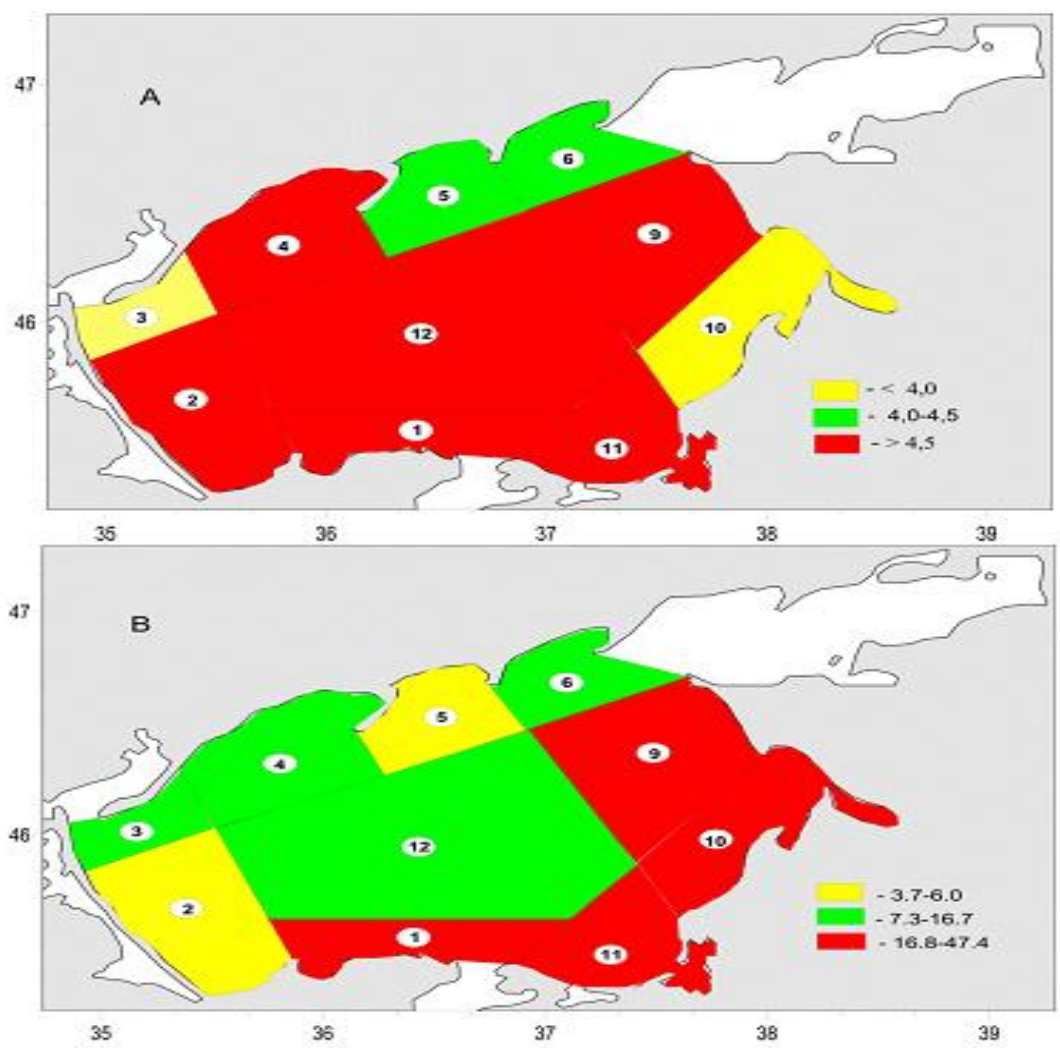

Рис. 1. Районирование Азовского моря по солености (промилле) - А и ВТХУВ (в тыс. усл. ед.) - В

Таблица 1. Значения ВТХУВ (в усл. ед.) по районам

\begin{tabular}{|l|c|c|c|c|c|c|c|c|c|c|c|c|}
\hline \multicolumn{1}{|c|}{ Район } & 2 & 5 & & 3 & 4 & 6 & 12 & 1 & 9 & 10 & 11 \\
\hline Минимум & -257 & 0 & & -1637 & -151 & -802 & 172 & -169 & -2662 & 24 & -3484 \\
\hline Максимум & 3418 & 6006 & & 9641 & 7170 & 15943 & 14635 & 25687 & 44745 & 20348 & 21546 \\
\hline Среднее & 1550 & 1988 & & 2011 & 1960 & 4097 & 3533 & 5582 & 5816 & 5175 & 5871 \\
\hline
\end{tabular}

В первую группу вошли прикерченский -1 и восточные $-9,10,11$ районы, где в наибольшей степени заметно распространение трансформированных пресноводных речных вод в поверхностном слое и соленых вод Керченского пролива в придонном слое в виде языка по направлению к Таганрогскому заливу [8].

Средней амплитудой характеризовались 3-й северо-западный и 4-й, 6-й северные районы, располагающиеся вдоль основного потока распресненных вод Таганрогского залива, а также центральный 12 район - зона смешения разнородных трансформированных вод.

Малая амплитуда отмечалась в относительно однородных по вертикальной структуре вод районах - 2-м западном, наиболее удаленном от воздействия рас- пресненных и соленых вод, а также 5-м северном со станцией наблюдения в относительно закрытом Бердянском заливе.

В группе районов с высоким уровнем изменчивости ВТХУВ: в 9-м притаганрогском диапазон значений устойчивости после 2006 по сравнению с предшествующим периодом снизился в 3 раза (с 45,7 до 15,7 тыс. усл. ед.); в 10-м восточном районе - в 2 раза (с 20,3 до 10,7 тыс. усл. ед.); в 1-м прикерченском и 11-м юго-восточном - всего на 3,6 тыс. усл. ед. (табл. 2, рис. 3).

В группе районов со средней изменчивостью ВТХУВ такое уменьшение диапазона - в основном в $2-2,5$ раза (с $7,3-$ 16,8 тыс. усл. ед. до 3,7-6,8 тыс. усл. ед.); в $12-$ м - незначительно (на 0,5 тыс. усл. ед.). 


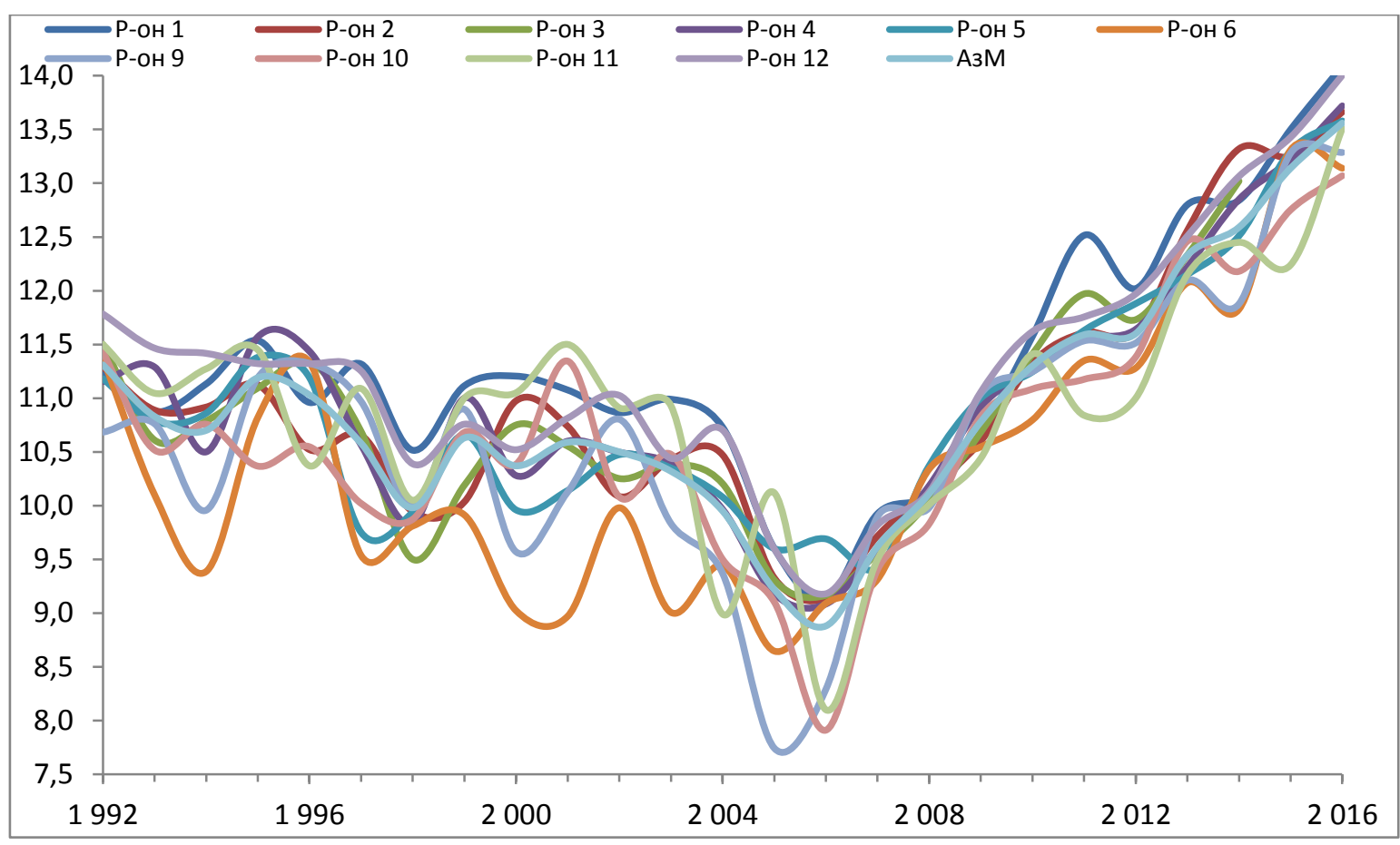

Рис. 2. Соленость поверхностного слоя Азовского моря и его районов в летние периоды 1992-2016 гг.

Таблица 2. Амплитуда межгодовой изменчивости значений ВТХУВ (в усл. ед.) по районам

\begin{tabular}{|c|c|c|c|c|c|c|c|c|c|c|c|}
\hline Район & 2 & 5 & & 3 & 4 & 6 & 12 & 1 & 9 & 10 & 11 \\
\hline $1992-2016$ & 3675 & 6006 & & 11278 & 7321 & 16750 & 14807 & 16745 & 47407 & 20324 & 25030 \\
\hline $1992-2006$ & 3675 & 6243 & & 11278 & 7321 & 16119 & 15133 & 25800 & 45701 & 20278 & 21401 \\
\hline $2006-2016$ & 3338 & 3491 & & 4432 & 3726 & 6852 & 14681 & 22155 & 15714 & 10723 & 18112 \\
\hline после 2010 & 1128 & 2974 & & 2227 & 3726 & 6229 & 6077 & 7783 & 5190 & 9196 & 15230 \\
\hline
\end{tabular}

В группе районов с низкой амплитудой значений ВТХУВ: во 2-м районе она оставалась практически неизменной весь период наблюдений, а в 5-м снизилась после 2006 г. в 1,8 раза - с 6,2 до 3,5 тыс. усл. ед.

Особенно заметно уменьшение значений ВТХУВ и амплитуды их межгодовых колебаний в районах после 2010 г. по сравнению с периодом 1992-2006 гг.: в 9-м - амплитуда снизилась в 9 раз, в 3 -м - в 5 раз, в остальных районах - в 1,5-3,5 раза, т.е. увеличилась степень однородности вод в последние годы.

Межгодовая тенденция изменчивости ВТХУВ в целом для всего периода наблюдений следующая:

- в 9-м районе резко отрицательный тренд и снижение устойчивости;
- в 3-4-м районах слабые рост и увеличение стратификации;

- остальные районы - небольшое уменьшение устойчивости.

Таким образом, в 9-м притаганрогском районе, вероятно, уменьшение адвекции разнородных вод: Таганрогского залива в поверхностном слое и Керченского пролива в придонном слое.

После 2010 г. во всех районах - отрицательный тренд межгодовой изменчивости ВТХУВ.

Межгодовая цикличность изменчивости ВТХУВ в основном 2-4 года; во 2, 4 и 5 районах с относительно низкой амплитудой такой изменчивости отмечались единичные 5-летние циклы (рис. 3).

Наибольшая повторяемость цикличности в основном 2-3 года, во 2-м районе $-4-5$. 


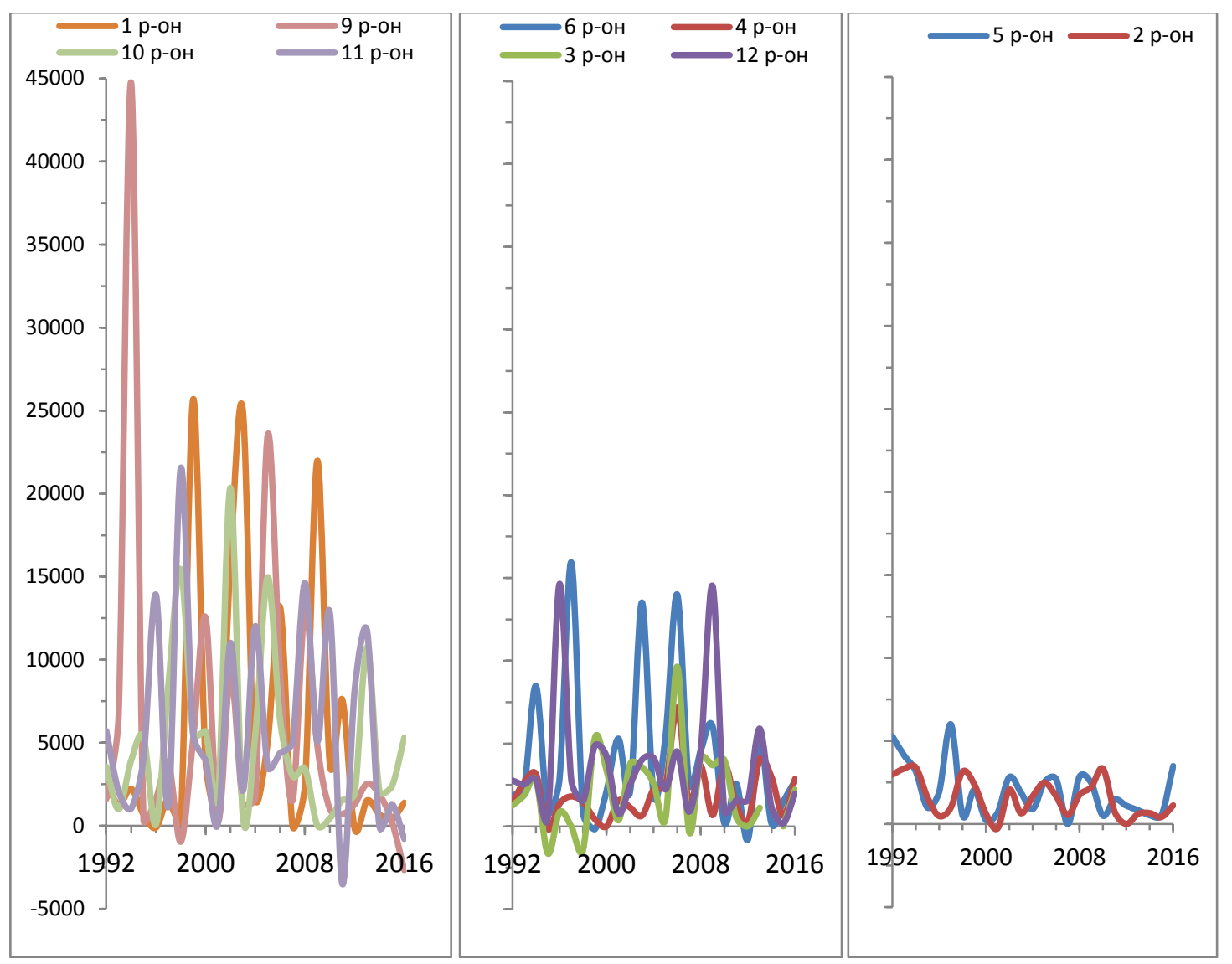

Рис. 3. ВТХУВ (в усл. ед.) в районах Азовского моря в летние периоды 1992-2016 гг.

Заключение. В ходе данного исследования был проведен пространственновременной анализ рядов наблюдений солености различных районов Азовского моря, который позволил выявить периоды как с отрицательным (1992-2006 гг.), так и положительным (2006-2016 гг.) трендами.

Были отмечены районы Азовского моря с максимальной (район, прилегающий к Керченскому проливу) и минимальной (северо-западный район) амплитудой изменчивости солености.

Период 1992-2006 гг. характеризовался короткопериодной цикличностью межгодовых колебаний солености, а 2006-2016 гг. - долгопериодной.

В период 1992-2006 гг. изменчивость солености имела разнонаправленный характер, в 2006-2016 гг. - относительно однонаправленный, характеризовавшийся стабильным осолонением. В конце периода наблюдений соленость во всех исследуемых районах выросла до $13-14 \%$.
Выделены 3 группы районов Азовского моря по межгодовой изменчивости ВТХУВ: с высокой (1, 9-11 районы), средней $(3,4,6,12$ районы), низкой $(2,5$ районы) ее амплитудой - соответственно приближенных к Таганрогскому заливу или Керченскому проливу, в зоне распространения распресненных вод Таганрогского залива или смешения вод в центре моря, в удаленной западной части моря или в относительно закрытом 5 районе.

После 2006 г. амплитуда межгодовой изменчивости ВТХУВ притаганрогских и северных районов (3-6, 9, 10 районы), находящихся под влиянием основного потока распространения относительно пресных вод Таганрогского залива, снизилась в основном в 2-3 раза; в центральном и южных районах $(1,2,11,12)$ - изменилась незначительно.

После 2010 г. это уменьшение в основном в 1,5-3,5 раза, в 3-м районе в 5 ра3, в 9-м - в 9, т.е. увеличилась степень однородности вод в последние годы. 
В целом для всего периода наблюдений тренд межгодовой изменчивости ВТХУВ в основном незначительный, в 9-м районе резко отрицательный, после 2010 г. - во всех районах отрицательный.

Межгодовая цикличность изменчивости ВТХУВ в основном 2-4 года, наибольшая повторяемость цикличности в большинстве районов - 2-3 года, во 2-м районе - 4-5.

Основной вывод - значительное увеличение солености после 2006 г. и уменьшение ВТХУВ после 2010 г. по всем районам моря, т.е. воды стали более солеными и однородными.

\section{СПИСОК ЛИТЕРАТУРЫ}

1. Экосистема Азовского моря: режим, продуктивность, проблемы управления. Часть I. Режим и продуктивность в период до зарегулирования стока рек / С.П. Воловик, И.Г. Корпакова, Е.А. Лавренова [и др.]. Краснодар: Кубанский гос. ун-т. 2008. 347 с.

2. Ильин Ю.П. Гидрометеорологические условия морей Украины. Том 1: Азовское море / В.В. Фомин, Н.Н. Дьяков, С.Б. Горбач. Севастополь: МЧС и НАН Украины, Морское отделение Украинского научно-исследовательского гидрометеорологического института, 2009. $402 \mathrm{c}$.

3. Куропаткин А.П. Изменение солености Азовского моря / А.П. Куропат- кин, С.В. Жукова, В.М. Шишкин [и др.] // Вопросы рыболовства. 2013. Т. 14. № 4 (56). C. 666-673.

4. Куропаткин А.П. Современные и перспективные изменения солености Азовского моря / А.П. Куропаткин, С.В. Жукова, В.М. Шишкин [и др.] // НаучноТехнический журнал. 2015. № 1. С. 7-15.

5. Куропаткин А.П. Закономерности формирования пространственно-временной структуры термогалинного расслоения вод Азовского моря / А.П. Куропаткин, С.В. Жукова, В.М. Шишкин [и др.] // Основные проблемы рыбного хозяйства и охраны рыбохозяйственных водоемов Азово-Черноморского бассейна: сб. науч. трудов (2012-2013). Ростов на/Д. 2014. С. 135-155.

6. Книпович Н.М. Гидрология морей и солоноватых вод (в применении к промысловому делу). М.: Пищепромиздат. $1938.513 \mathrm{c}$.

7. Федосов М.В., Виноградова Е.В. Основные черты гидрохимического режима Азовского моря // Труды ВНИРО. 1955. Т. 31. Вып. 1. М. С. 9-35.

8. Куропаткин А.П. Исследование изменений пространственно-временной структуры полей солености в Азовском море // Режим и биологические ресурсы Азово-Черноморского бассейна: Проблемы устойчивого развития рыбного хозяйства: материалы Междунар. науч. конф. (г. Ростов-на-Дону, 17-19 декабря 2003 г.). Ростов на/Д. 2003. С. 92-103.

\title{
INTER-ANNUAL VARIABILITY OF SALINITY AND VERTICAL THERMOHALINE STABILITY IN THE DIFFERENT AREAS OF THE SEA OF AZOV IN SUMMER SEASON OF 1992-2016
}

\author{
A.T. Kochergin ${ }^{1}$, S.V. Zhukova ${ }^{2}$, Ye.Yu. Malygin ${ }^{3}$ \\ ${ }^{1}$ Kerch Branch ("YugNIRO") of the Azov Research Institute for Fisheries, the RF, Kerch, Sverdlov St., 2 \\ ${ }^{2}$ Azov Research Institute for Fisheries, the RF, Rostov-na-Donu, Beregovaay St., $21 \mathrm{~V}$ \\ ${ }^{3}$ Russian State Hydrometeorological University, the RF, Saint Petersburg, Malookhtinsky Prospect, 98
}

Based on the multi-annual data on salinity and vertical thermohaline stability of the waters in summer seasons of 1992-2016, inter-annual variability of these parameters has been analyzed for different areas of the Sea of Azov. Trends, cycles, magnitudes have been identified, zoning of the sea in line with the pattern of temporal variability of salinity and vertical thermohaline stability has been carried out. The years that were pivotal for trends in inter-annual development of the analyzed parameters were specified, as well as the areas of their relatively high and low dynamics of temporal variability.

Keywords: the Sea of Azov, salinity, stability, inter-annual variability, trend, repeating pattern. 